\title{
Modes of Brassinosteroid Activity in Cold Stress Tolerance
}

\author{
Veronica E. Ramirez and Brigitte Poppenberger* \\ Biotechnology of Horticultural Crops, School of Life Sciences Weihenstephan, Technical University of Munich, Freising, \\ Germany
}

Cold stress is a significant environmental factor that negatively affects plant growth and development in particular when it occurs during the growth phase. Plants have evolved means to protect themselves from damage caused by chilling or freezing temperatures and some plant species, in particular those from temperate geographical zones, can increase their basal level of freezing tolerance in a process termed cold acclimation. Cold acclimation improves plant survival, but also represses growth, since it inhibits activity of the growth-promoting hormones gibberellins (GAs). In addition to GAs, the steroid hormones brassinosteroids (BRs) also take part in growth promotion and cold stress signaling; however, in contrast to Gas, BRs can improve cold stress tolerance with fewer trade-offs in terms of growth and yields. Here we summarize our current understanding of the roles of BRs in cold stress responses with a focus on freezing tolerance and cold acclimation pathways.

Reviewed by:

Trevor M. Nolan,

Duke University, United States

Yanhai Yin,

lowa State University, United States

*Correspondence:

Brigitte Poppenberger brigitte.poppenberger@tum.de

Specialty section: This article was submitted to

Plant Physiology,

a section of the journal

Frontiers in Plant Science

Received: 15 July 2020 Accepted: 09 October 2020 Published: 06 November 2020

Citation: Ramirez VE and Poppenberger $B$ (2020) Modes of Brassinosteroid Activity in Cold Stress Tolerance.

Front. Plant Sci. 11:583666. doi: $10.3389 /$ fpls.2020.583666

\section{INTRODUCTION}

Cold stress represents a substantial risk for plant growth and development and impacts on plant distribution and crop production. Both chilling $\left(>0^{\circ} \mathrm{C}\right)$ and freezing $\left(<0^{\circ} \mathrm{C}\right)$ temperatures can cause damage, with the degree depending on the species and the developmental stage during exposure. Plants are most susceptible to frost during periods of active vegetative and reproductive growth, since growing, hydrated tissues are especially vulnerable to injury caused by freezing of cellular fluids (Nishiyama, 1995). Also at high risk is plant reproductive development, where both structural and functional abnormalities can lead to failed fruit and seed production (reviewed in Thakur et al., 2010; Albertos et al., 2019). Consequently, frost in spring during the bloom of fruit trees or stem elongation of winter cereal crops can result in a complete loss of harvest (Chmielewski et al., 2004; Augspurger, 2013).

It is therefore perhaps not surprising that cold stress has significant economic impact. For example, the United States in the mid 20th century experienced more economic losses due to frost damage than to any other weather-related phenomenon (White and Haas, 1975). As a land spanning a range of climates, many of the southern subtropical and warm temperate latitudes are areas of horticultural and agricultural significance. Various fruit crops in these areas are vulnerable to frost, as physical damage to produce hinders ideal growth and reduces yield quality 
and quantity. Recent trends in winter-related damages also show an increasing number of incidents in the past century (Figure 1). In 2018, Harvey reported that up to $60 \%$ of locations across North America, Europe, East Asia, and parts of South America would see extreme weather events triple, much of which can be attributed to recent shifts in Arctic temperatures impacting the seasonal polar vortex.

Global warming is expected to further increase the risk of damage by frost in particular in mid-latitude zones where many major cropping areas lie. One such observation is the arctic amplification reduction of the pole-to-mid-latitude temperature gradient, predicted to cause more extreme weather events and extended conditions, such as early thaws, and sudden cold spells (Francis and Vavrus, 2012). The rising temperatures result in prolonged growing seasons, which delays cold hardening in fall and accelerates de-hardening in spring, increasing the potential for damage when early or late frosts occur (Rigby and Porporato, 2008; Augspurger, 2013; Hatfield and Prueger, 2015). Even in winter de-hardening could occur when temperatures rise periodically (Rapacz et al., 2017). Breeding for optimized cold stress tolerance may contribute to a possible solution, but has been mostly unsuccessful, as cold stress tolerance is usually correlated with impaired growth. This is supported widely by evidence that abiotic stress, including cold stress, represses growth, especially in scenarios of compounded stress or deprivation factors (Mittler, 2006). Growth repression is thought to free resources for other energy-demanding, stress-protective cellular reactions and systemic signaling (Mittler, 2002), although this hypothesis remains to be validated. Therefore, a thorough understanding of cold stress responses and how they are integrated with growth regulatory pathways is required for the design of targeted breeding approaches that aim to improve cold tolerance without trade-offs on growth or yield.

The repression of growth in response to cold involves effects on growth-promoting hormones and in this context, gibberellins (GAs) play an important role, although also other hormones are involved (reviewed in Eremina et al., 2016a). A reduction of GA levels and signaling activity contributes to restraint growth and enhances plant tolerance to several abiotic stress types including cold, drought, and osmotic stress (Achard et al., 2006, 2008; Magome et al., 2008). In addition to GAs, also the brassinosteroids (BRs) exhibit dual functions in growth control and abiotic stress protection. However, as opposed to GAs, there is evidence that BRs can promote both growth and resistance against certain abiotic stress types, which is intriguing since it may provide a means to increase abiotic stress tolerance with fewer trade-offs. A number of reviews have summarized progress in this area, providing an excellent overview of signaling events implicated in different abiotic stress types (reviewed in Divi and Krishna, 2009; Vriet et al., 2012; Planas-Riverola et al., 2019; Nolan et al., 2020). Here we have specifically focused on the role of BRs in cold stress responses and lay an emphasis on cold acclimation and freezing tolerance. While the resumption of growth after cold stress exposure is certainly also a relevant and exciting research area (reviewed in Vyse et al., 2019), evidence on the function of BRs in this process is still very

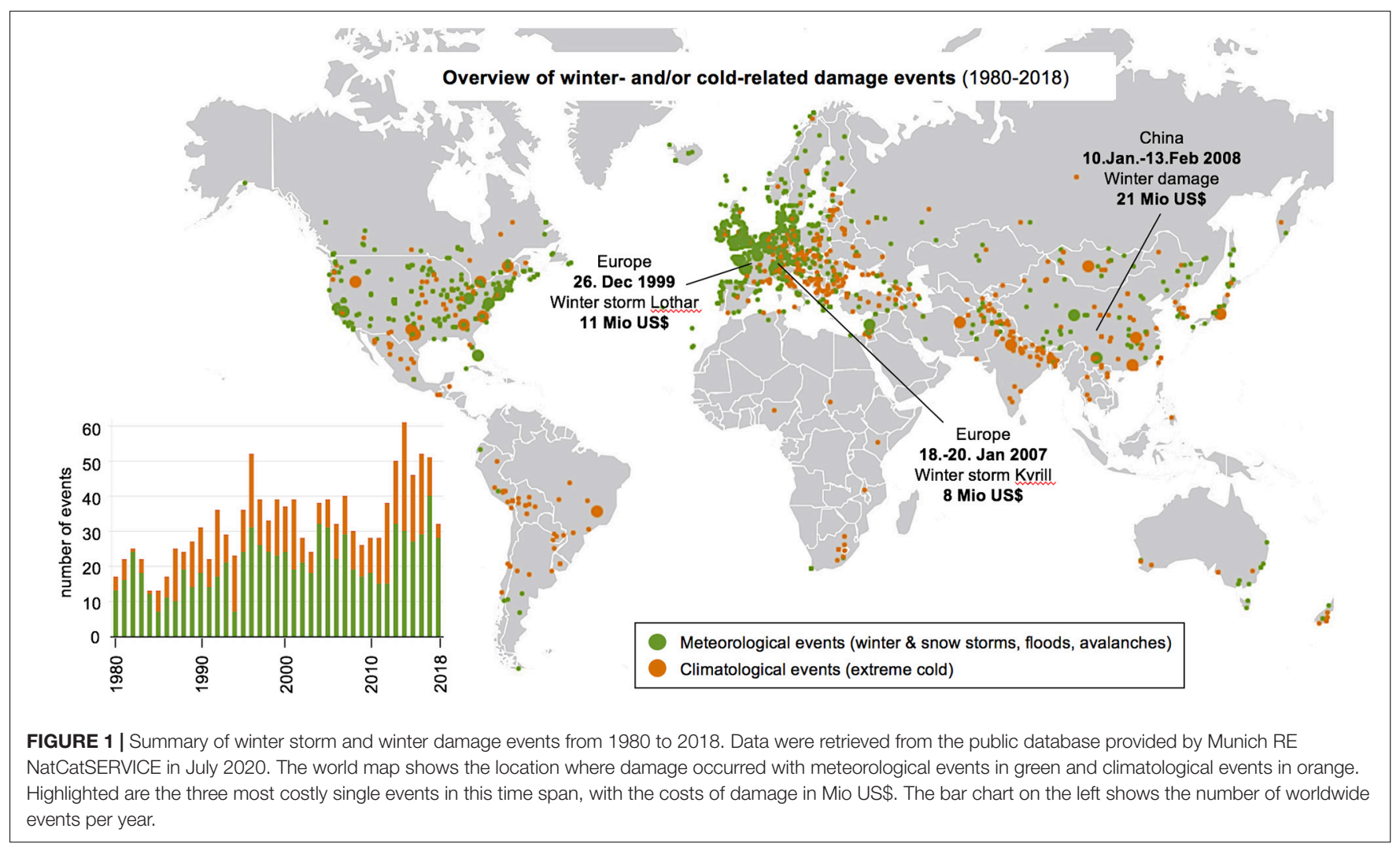


limited (Pagter et al., 2017) and thus we do not expand on this topic here.

\section{BRASSINOSTEROIDS AND THEIR ROLE IN PLANT GROWTH AND FROST TOLERANCE}

Brassinosteroids are steroid hormones that are synthesized from the bulk sterol campesterol by multiple hydroxylation and oxidation events, which are catalyzed by different cytochrome P450 enzymes, including DWARF4 (DWF4), CONSTITUTIVE PHOTOMORPHOGENESIS AND DWARFISM (CPD), ROTUNDIFOLIA 3 (ROT3), and the CYP85A2 BR6ox2 (Clouse, 2011). The end products of BR biosynthesis castasterone (CS) and brassinolide (BL) are bioactive; they act in minute concentrations, which are closely monitored and adjusted. This is executed by regulation of genes involved in BR biosynthesis and catabolism, depending on the needs of intrinsic growth programs, but also according to requirements for growth adaptation and stress protection (reviewed in Clouse, 2011; $\mathrm{Lv}$ and $\mathrm{Li}, 2020$ ). With respect to cold stress, there is evidence that the BR biosynthetic genes DWF4, CPD, and BR6ox2 are rapidly downregulated by cold treatment (Eremina et al., 2016b). In particular, BR60x2 is repressed by one order of magnitude in plants exposed to $4^{\circ} \mathrm{C}$, which is significant given that $\mathrm{BR}$ responses are usually only in the range of two to fourfold (Goda et al., 2002). Whether this repression of BR-biosynthetic genes also impacts BR levels and is of importance for BR-enabled effects in cold stress protection remains to be shown.

Castasterone and BL confer their bioactivity by binding to BR receptors of the BRASSINOSTEROID INSENSITIVE 1 (BRI1)-type, which initiates a phosphorylation-dependent signal transduction cascade that requires co-receptors, including BRI1-ASSOCIATED RECEPTOR KINASE 1 (BAK1) and BRI1KINASE INHIBITOR 1 (BKI1), multiple phosphatases, including BSU1, and kinases, the most-studied being the GSK3/shaggylike kinase BRASSINOSTEROID INSENSITIVE 2 (BIN2). BIN2 is a central repressor of BR signaling and, among other targets, also directly regulates BR-regulated transcription factors (TFs) that control BR-responsive gene expression (Kim and Wang, 2010). These TFs include different classical bHLH proteins such as BRASSINOSTEROID ENHANCED EXPRESSION 1-3 (BEE1BEE3) and CESTA (CES), the BES1-INTERACTIVE MYC-LIKE (BIMs), and PHYTOCHROME INTERACTING FACTOR 4 (PIF4), but also atypical bHLH-type proteins, most importantly the BRI1-EMS-SUPPRESSOR 1/BRASSINAZOLE RESISTANT 1 (BES1/BZR1) subfamily (Wang et al., 2002; Yin et al., 2005; Bernardo-García et al., 2014; Khan et al., 2014).

Clear evidence for BRs being essential for plant development is the severe phenotypes of BR-deficient mutants. The most prominent features are dwarf growth with dark-green, cabbagelike leaves in the light, de-etiolated development in the dark, late flowering, and impaired fertility (reviewed in Clouse, 2011). Some of these defects are caused by malfunctioning cross-talk with GAs, since in certain plant species, including the model plant Arabidopsis thaliana and rice, BRs can promote GA biosynthesis
(Tong et al., 2014; Unterholzner et al., 2015) and also interplay with GAs at the signaling level (reviewed in Tong and Chu, 2016; Unterholzner et al., 2016).

Severe growth defects represent a challenge when stress phenotypes are to be studied, since strong morphological alterations can impact stress perception. Therefore, multiple mutant settings and BR application studies were applied when the impact of BRs on freezing tolerance was assessed. This yielded solid evidence that BRs can improve frost tolerance. On the one hand, BR application increased survival rates of plants exposed to subzero temperatures (Kagale et al., 2007; Kim et al., 2010). On the other hand, and more importantly, A. thaliana mutants, deficient in various steps of BR signaling including the strong bri1-1 and the weak bri1-301 allele, and over-expression lines of BIN2 and its homolog ASKtheta, showed decreased frost tolerance. In line, the BRI1 over-expression line 35S:BRI1GFP and the higher-order bin2-3 bill bil2 mutant, plants with constitutively active BR signaling, were more resistant to frost damage (Kim et al., 2010; Eremina et al., 2016b; Li et al., 2017). Interestingly, in addition to improving basal tolerance, BRs also contribute to acquired freezing tolerance in A. thaliana, which involves complex molecular and biochemical changes that are induced by low, but non-freezing temperatures, in a process termed cold acclimation.

\section{BIOCHEMICAL AND CELLULAR EVENTS DURING COLD STRESS}

Cold acclimation enables plants from temperate geographical zones to increase their basal levels of freezing tolerance through initiation of a multitude of biochemical and cellular changes. These changes are induced by cold, but non-freezing temperatures and include compositional changes to the cell wall and membrane, an activation of anti-oxidative mechanisms, and the synthesis and accumulation of cryoprotective solutes, amino acids, and proteins (Lissarre et al., 2014).

Frost damage can be caused by the freezing of soil waters leading to drought exposure, and by the freezing of cellular fluids, equally as problematic. The development of ice depends on the presence of ice nucleation sites, which may be intrinsically found in cells or cell walls, or formed by epiphytic bacteria found on leaves (Lindow et al., 1982). Although the formation of ice crystals is usually initiated in the cell walls and the intercellular space, it is the cellular water-deficit caused by both the lower chemical potential and vapor pressure of ice that actively dehydrates the cell. Water in the cytoplasm or vacuole moves down the potential water gradient toward extracellular ice, and across the plasma membrane (Buchanan et al., 2000). Freezing damage therefore induces cellular desiccation and rigidification of the cell membrane as it contracts and pulls away from the cell wall (Taiz et al., 2015; illustrated in Figure 2). Similar to the effects of drought stress, the symplast can lose about $90 \%$ of osmotically active water to the apoplast, putting already semidehydrated cells at risk for additional injury, in particular to further suffer membrane damage, which results in the loss of physical integrity of the cells (Taiz et al., 2015). On affected 


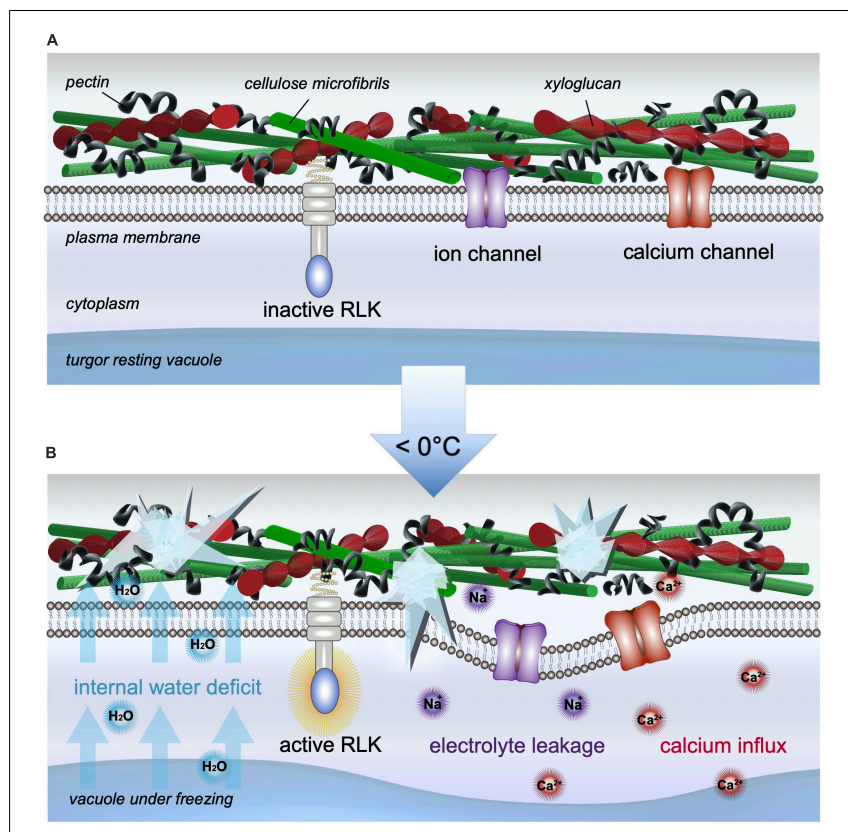

FIGURE 2 | Cellular changes induced by freezing stress. (A) At ambient temperatures, the cell wall and membrane, as well as other cellular compartments, are intact and the cell is in a normal resting state, which ensures water and cellular volume homeostasis. (B) In the event of freezing stress, ice formation in the apoplast induces a movement of water out of the cell, which results in an internal water deficit, mimicking dehydration. If exposure is prolonged, intracellular ice may form, rupturing the plasma membrane, causing activation of RLKs, electrolyte leakage, calcium influx, and cell death, when the membrane eventually pulls away from the cell wall.

plants, wilting and water-soaked areas appear; when dried these form necrotic lesions on leaves, fruits, or stems (Morel and Dangl, 1997). While one obvious consequence may include the depreciation of aesthetic worth, the nutritional value, longevity, and overall yield may ultimately be compromised.

Frost itself is not a solitary threat; temperatures above zero $0^{\circ} \mathrm{C}$ can be problematic, especially for species that stem from tropical and subtropical geographical zones. Chilling can induce disruption of photosynthetic pathways, which activates photochemical production of reactive oxygen species (ROS) that cause injury to DNA, proteins, and lipids (Gururani et al., 2015). To prevent harm, plants utilize ROS scavenging enzymes and antioxidants such as ascorbate and glutathione (Mittler et al., 2004). In addition, denaturation of proteins, loss of guard cell function, and increased tissue levels of $\mathrm{CO}_{2}$ are observed (Allen and Ort, 2001). While chilling damage is evidently not attributed to ice crystal formation, it impacts on the plants ability to accommodate low temperatures with loss of membrane fluidity, resulting in membrane leakage (Verslues et al., 2006) and it appears that BRs can protect from the damaging effects of these events. BR application improved plant performance in the cold, which was shown for the chilling-sensitive species Cucumis sativus (cucumber), Solanum lycopersicum (tomato), Oryza sativa (rice), Zea mays (maize), and also for the cold-hardy plant A. thaliana (He et al.,
1991; Katsumi, 1991; Kagale et al., 2007; Koh et al., 2007; Xia et al., 2009; Aghdam et al., 2012). Moreover, over-expression of DWF4 conferred protective effects during germination and early seedling development of $A$. thaliana at $4^{\circ} \mathrm{C}$ (Divi and Krishna, 2009) and reduced chilling-induced oxidative damages in tomato (Xia et al., 2018). As a majority of high-value horticultural crops fall under the chilling-sensitive category, the function and efficacy of BR application demands a thorough understanding as to how each phase of injury may be transmitted, and this will be detailed here.

\section{Physical and Structural Changes During Cold Stress: The Cell Wall}

The primary cell wall consists of a hemicellulose, pectin, and a structural protein matrix, amid an integrated network of cellulose microfibrils. In a normalized metabolic state, the proteins act as reinforcing structural components, operating together similar to an exoskeleton layer, resisting forces of turgor pressure, and controlling cell expansion (Taiz et al., 2015). The cell wall not only works as a diffusion barrier for ions and macromolecules, but it limits the range of molecules that can reach the plasma membrane by selective permeability and hydrophobic interactions, maintained by an intrinsic negative charge. In the event of perceived chilling stress, the membrane becomes rigid as protein conformations change and complexes destabilize. The level of susceptibility to cold-dependent conformational changes also depends on the cell type; typically, thicker cells walls are found in sclerenchyma cells (epidermal cells, xylem, phloem, and tracheids). The type and function of a plant cell also influences whether it is composed of a primary wall or secondary wall, which vary in development and protein and polysaccharide profiles.

Cell expansion and compression resistance rely on the abundance of pectin, which is found at relatively high levels in primary cell walls. Alternately, secondary cell walls contain dense structures mostly of cellulose-hemicellulose and lignin. These polysaccharide components determine stability, flexibility, and permeability; in the context of BRs in cold stress, evidence suggests BR signaling pathways to be involved with cell wall remodeling mechanisms responsible for altering these features (Rao and Dixon, 2017). In maize, wheat, and rice, for instance, the expression of many xyloglucan transferase/hydrolase enzymes (XTHs) and expansin genes was reported to be regulated by BRs (Uozu et al., 2000). XTHs catalyze cleavage of xylogulcan polymers then transferring ends to other xyloglucan chains, while expansins loosen linkages between cellulose microfibrils initiating cell wall loosening, a protective reaction against abiotic stresses (Yennawar et al., 2006). Such structural flexibility may allow a plant to survive harsh conditions with extreme humidity or temperature fluctuations.

Brassinosteroids have also been found to play an essential role in secondary cell wall formation. In A. thaliana, it was shown that BR signaling regulates secondary wall development via BRinduced BES1 activation of VND6 and VND7 (Yang and Wang, 2016), which determine xylem cell transition to form tracheary elements and alter the expression of MYB TFs that regulate lignin biosynthesis (Ohashi-Ito et al., 2010). Moreover, in A. thaliana, a 
loss of function of DIMINUTO1 (DIM1/DWF1), an enzyme that catalyzes an early step in BR biosynthesis, caused a phenotype with a significant reduction in lignin content and a lower lignin syringyl to guaiacyl ratio (Hossain et al., 2012). Lignin is the second most abundant carbon sink in plants; it is deposited in the secondary cell wall, augmenting cell wall rigidity and providing structural support, yet remaining clear of the primary cell wall (Karkonen and Koutaniemi, 2010); evidence that BRs can increase the accumulation of lignin has been implicated in the direct binding of BES1/BZR1 to promoter regions NAC and MYB TFs integral to lignin synthesis pathways (Benatti et al., 2012).

Alternately, pectin allows cell walls to remain firm, inhibiting collapse of the cellulose matrix, but also conferring flexibility, by forming hydrated gels, responsive to changes in polymer residues or $\mathrm{pH}$ (Voxeur and Hofte, 2016). In A. thaliana, BAK1 can interact with a plasma membrane receptor-like protein, RLP44, to repress pectin methylesterase inhibitor activity, reducing the rigidity of the pectic matrix and stimulating cell wall loosening in both basal and stressed conditions (Wolf et al., 2014). Although these implications of BR signaling in cell wall formation point to a significant contribution in cold stress tolerance, this area still requires further investigation.

In the event of cold exposure, both fluidity and strength of the cell wall influence internal cellular water conditions. Freezing especially alters the movement of water as intercellular ice forms. Ice formation occurs first in the apoplast where the negative water potential is far lower, eliciting further water movement down the gradient. Subsequently, an internal water deficit develops, mimicking the effects of cell dehydration (reviewed in Yamada et al., 2002; Le Gall et al., 2015). Moreover, freezing may induce intracellular ice crystal formation, and subsequently, wall destruction and cell death (reviewed in Tenhaken, 2015). As ice crystals grow, they puncture into the cytoplasm, rupturing membranes, and the membranes of nearby organelles. Both cellular desiccation and rigidification of the cell membrane continue as the membrane contracts and pulls away from the cell wall (Taiz et al., 2015). When the membrane then starts to break, an influx of calcium and electrolyte leakage occurs (illustrated in Figure 2), which is measurable and often serves as a quantifiable read-out for frost-induced damage.

\section{Membrane Fluidity}

Exposure to cold or frost affects not only the permeability, flexibility, and resilience of the primary cell wall but if severe, may damage the plasma membrane. Low temperatures induce a hardening of the cell membrane, and a number of studies on cold perception suggest a dependency on membrane fluidity changes (Markovskaya and Shibaeva, 2017). As a major site of freezing-induced injury, the plasma membrane undergoes structural changes, a consequence of cellular dehydration (reviewed in Ingram and Bartels, 1996). When stages of cellular desiccation progress, the plasma membrane draws inward, away from the cell wall and closer to organelle membranes, both altering and destabilizing the integrity of membrane components, predominantly lipids and proteins (reviewed in Thomashow, 1999).
Under ambient growth conditions, each membrane in the plant cell has characteristic heterogeneous lipid profiles, and each class of lipids an equally distinct fatty acid composition. One such class of lipids are sterols, and include campesterol; as $\mathrm{BR}$ precursors, and central membrane components, they regulate membrane fluidity and permeability of membranes by directly affecting the activity of membrane-bound or membrane-associated proteins. As such they play a range of roles, from mature membrane protein signaling to inducing hyperpolarization of the membrane in cell division (reviewed by Clouse, 2011). Altered sterol profiles in BR mutants may affect membrane structure, influencing how specific signaling proteins interact, and impacting the fluidity of the membrane in response to environmental cues (Clouse, 2002). Although the current knowledge of membrane fluidity and BR signaling focuses on membrane-bound receptor activity and downstream signaling targets, other cell interactions like the ER-localized Unfolded Protein Response have been recently described to play a role both in protecting reproductive development stages from extreme temperatures and BRmediated responses by recruiting the membrane-associated TFs bZIP17 and bZIP2 (Che et al., 2010; Bao and Howell, 2017). Rigidification of the membrane and alteration of lipid profiles may be resolute structural responses to cold exposure; however, further investigation of membrane-compartment interactions in vulnerable developmental stages may provide insight into otherwise cryptic BR-mediated signaling.

\section{$\mathrm{Ca}^{2+}$ Influx}

A key molecular messenger prone to accumulation following cold perception is the divalent calcium cation $\mathrm{Ca}^{2+}$. In the cell, cytosolic calcium is normally maintained at low resting concentrations to facilitate external and internal $\mathrm{Ca}^{2+}$ membrane transport. Organelles including the rough ER and the vacuole contain intracellular stores of $\mathrm{Ca}^{2+}$ ready for signal-induced mobilization. The primary calcium receptor, calmodulin, is a highly conserved $\mathrm{Ca}^{2+}$ calcium binding protein attached to the plasma membrane, also found in both nuclear and cytoplasmic compartments. In the event of cold perception, a signal initiates channel-mediated, inward calcium transport. These channels are either activated mechanically by cell wall rigidification, or through direct ligand binding (Lissarre et al., 2014). It has been suggested that $\mathrm{Ca}^{2+}$ spiking is regulated by downstream receptor-like kinases with leucine-rich-repeat domains similar to those of the BR receptors (Oldroyd and Downie, 2004) and there is evidence that BRs can impact on the activity of $\mathrm{Ca}^{2+}$ channels (Straltsova et al., 2015); albeit, the modes are still unknown.

In A. thaliana, $\mathrm{CaM}$ (calmodulin) binds in a $\mathrm{Ca}^{2+}$-dependent manner to the cytoplasmic domain of BRI1 (Oh M. H. et al., 2012). Since BR signal transduction is initiated by hormone perception in the extracellular domain of BRI1, which then binds to BAK1, activating phosphorylation of cytoplasmic residues in the kinase domain by $\mathrm{Ca}^{2+} / \mathrm{CaM}$ binding may attenuate kinase activity of BRI1 and influence subsequent signaling and downstream target regulation (Du and Poovaiah, 2005; Oh et al., 2009). 
$\mathrm{Ca}^{2+}$ binding to $\mathrm{CaM}$ has also been shown to be critical for BR biosynthesis and plant growth since it was found that DIM/DWF1 is a $\mathrm{Ca}^{2+} / \mathrm{CaM}$-binding protein and that calmodulin-binding compromises DWF1 function in planta (Du and Poovaiah, 2005). DWF1 orthologs in other plant species have a similar $\mathrm{Ca}^{2+} / \mathrm{CaM}$ binding motif, indicating that $\mathrm{Ca}^{2+} / \mathrm{CaM}$ regulation of DWF1 and DWF1 homologs is conserved among plants (Du and Poovaiah, 2005). The possibility for a role of CaM in BR biosynthesis is also indicated by the fact that CaM over-expression lines show phenotypic features of plants over-expressing the BR biosynthetic gene DWF4 (Du and Poovaiah, 2005). Consequently, the $\mathrm{Ca}^{2+} / \mathrm{CaM}$ complex may regulate a wide range of factors on the biosynthesis path of BRs in addition to LRR RLK co-receptor activity.

\section{ROS Species: Antioxidant Mobilization}

Most reactions involving enzymatic kinetics interact with photosynthetic processes and metabolite accumulation to maintain a state of survival. ROS accumulate as a result of fewer scavenging enzymes and the disturbance of metabolic activity in response to abiotic stresses such as lowered temperatures or drought (Choudhury et al., 2017). Furthermore, over-reduction of the chloroplast electron chain may further increase ROS formation, leading to photoinhibition of PSI and PSII (Tjus et al., 2001). High concentrations of ROS lead to deterioration of membranes, causing membrane leakage of solutes, initiating a signal cascade responsive to the source of injury (Ruelland et al., 2009).

There is evidence that points to a BR function in the activation of cell-wall centered defense by ROS. In response to physical damage or pathogen inoculation, oxylipins, or oxygenated fatty acid products, might function as ROS signals to activate the BR pathway thereby reinforcing the cell wall defensively (Marcos et al., 2015). Furthermore, BRs may have an effect on bond integrity of monolignol polymers and phenolic acids in the cell wall by regulating antioxidant enzymes at both the transcriptional and post-transcriptional level (Li et al., 2016).

The exogenous application of BR increases the activity of antioxidant enzymes appreciably, including superoxide dismutase, catalase, ascorbate peroxidase, and peroxidase in grains exposed to high metal stress (reviewed in Kumar et al., 2015). This is thought to strengthen the mechanical properties of the wall by enhancing the covalent cross-linked components through combined peroxidase activity increase and ROS formation (Tenhaken, 2015). By utilizing the antioxidant defense system and facilitating cross-linking of phenolic compounds in the cell wall, BRs may orchestrate the alleviation of ROS-burst induced oxidative damage (Kumar et al., 2015).

Additionally, it has been reported that BRs play a role in the induced transcription of an NADPH oxidase-encoding gene, leading to increased levels of apoplastic $\mathrm{H}_{2} \mathrm{O}_{2}$. This rapid accumulation affects developmental and stress response activity by inducing biosynthesis of the plant hormone abscisic acid (ABA) and stomatal closure. By prolonging $\mathrm{H}_{2} \mathrm{O}_{2}$ accretion, it is suggested that BRs control ROS homeostasis to induce a level of plant stress tolerance (Xia et al., 2015). Moreover, BR-induced stimulation of antioxidant enzymes in response to high ROS levels appears to be relevant for ROS detoxification and thus plant survival following cold stress (Bajguz and Hayat, 2009; Liu et al., 2009).

\section{Biochemical and Physiological Changes Toward Acclimation}

While many economically important crops are considered coldsensitive, chilling-resistant plants such as A. thaliana are able to grow and develop even in low temperatures of $0-12^{\circ} \mathrm{C}$, albeit at reduced rates. This adaptive capacity can be explained by diverse biochemical and physiological changes both in cell structure, and production of sugars, fatty acids, and secondary metabolites (Ruelland et al., 2009). In A. thaliana, various aminoacids including asparagine, aspartate, glutamate, glutamine, and alanine accumulate in response to cold (Klotke et al., 2004). Although a range of solutes accumulate, localization and therefore function vary within the cell. The trisaccharide raffinose, for instance, translocates from the cytosol to the chloroplasts, thereby protecting photosystems against damage in freeze-thaw phases (Knaupp et al., 2011). Conversely, in the plasma membrane, it behaves dispensably by replacing water molecules in the hydration shell of the lipid headgroups, preventing injurious lipid phase shifts.

Compositional changes in cell membrane lipid profiles are one of a series of physiological adjustments to cold conditions. In many cases, de-polymerization of the cytoskeleton in combination with phospholipid desaturation in the membrane can create an adaptive circumstance where the membrane rigidification is partially counterbalanced (Tasseva et al., 2004). Other responses to chilling include the plant increasing phospholipids or cerebrosides to prevent further membrane apposition and collapse.

While modifications improving structural integrity of the cell alleviate physical destruction, the accumulation of secondary metabolites may involve more complex pathways relying on gene regulation, expression, and modes of signal transduction (Shinozaki et al., 2003). Phenylpropanoids are a large group of secondary metabolites that comprise flavonoids, ubiquitous compounds involved in both abiotic and biotic stress defense mechanisms (Janská et al., 2010). Although well known for its role in fruit and leaf tissue pigmentation, UV protection, and photosynthetic interactions, very little is known regarding flavonoid pathway regulation in plants exposed to low temperatures, or its activity related to hormone signaling pathways, such as BRs. Petridis et al. (2016) described the change of a phenylpropanoid accumulation profile in BEE1 and GFR (G2-LIKE FLAVONOID REGULATOR) mutants following low temperature exposure, defined by quercetins and scopolin accumulating less, and anthocyanins accumulating more than in wild-type. These phenotypes formed the basis of further work, which showed that BEE1 and GFR act as negative regulators of anthocyanin accumulation by inhibiting anthocyanin biosynthesis genes, via suppression of the bHLH protein encoding genes TRANSPARENT TESTA8 (TT8) and GLABROUS3 (GL3) (Petridis et al., 2016). While BRs that act 
upstream of BEE1 have not been implicated into the complex rerouting of metabolic responses to low temperature, these data clearly imply BEE1 and potential redundantly acting factors as regulator(s), warranting further research in this field.

\section{COLD STRESS SIGNALING EVENTS}

\section{COR Gene Regulation}

In addition to the many changes that occur at the biochemical and morphological level, cold has a profound impact on the transcriptome; in A. thaliana, more than 2.500 genes are regulated by cold stress (Park et al., 2015). It can be assumed that the activation of cold responsive (COR) genes enables chilling stress protection and cold acclimation for increased freezing tolerance in capable plant species, although many of the described physiological events that take place when cold stress occurs have not been linked to up-stream signaling cascades as yet, and the sequence of events following cold stress exposure is often unclear.

$C O R$ gene regulation occurs in waves, is transient, and is realized by TFs. First wave TFs are activated at early time-points after cold perception and include ZAT10, ZAT12, HSFC1, CZF1, and ZF (Park et al., 2015). The by far best-characterized TFs that take part, however, are the C-REPEAT BINDING FACTORS (CBFs), also known as DROUGHT-RESPONSIVE ELEMENTS BINDING (DREB) factors, CBF1 (DREB1b), CBF2 (DREB1c), and CBF3 (DREB1a).

\section{BR Impact on the CBF Regulon}

The CBFs are AP2/ERF family TFs that bind to the C-repeat (CRT)/dehydration-responsive element (DRE), a motif found in promoters of genes activated by cold stress, drought, or high salt exposure (Park et al., 2015). In A. thaliana, the CBF regulon of COR genes comprises 133 induced genes, including COR15A, COR15B, COR47, COR78/RD29a, KIN1, and KIN2 which are often used as read-outs, and 39 repressed genes (Park et al., 2015). In $c b f 1,2,3$ triple mutants, which were generated using the CRISPR/Cas9 technology, basal freezing tolerance and cold acclimation are strongly compromised, providing conclusive evidence for the important role CBFs play in cold stress response (Zhao et al., 2016). Over-expression of CBFs increases freezing tolerance, as well as tolerance to drought and salinity in various plant species (Jaglo-Ottosen et al., 1998; Achard et al., 2008); however, it additionally causes dwarfism (Achard et al., 2008; Hu et al., 2015). This is attributed to the fact that CBFs promote expression of GA20x3 and GA2ox6, which encode enzymes that inactivate GAs, and of RGL3, a DELLA protein that represses GA responses (Achard et al., 2008; Park et al., 2015). Since the expression of $C B F$ s and a large set of CBF-induced genes is constitutively decreased in the BR-deficient mutants bri1-1 and bri1-301 (Eremina et al., 2016b), whereas it is constitutively increased in BRI1 over-expressing plants (Kim et al., 2010; Eremina et al., 2016b) and the bin2-3 bill bil2 triple mutant (Li et al., 2017), there is clear evidence that $B R s$ are required for $C B F$ transcription in basal, non-acclimated conditions.

CBF expression is controlled by multiple upstream TFs (illustrated in Figure 3), the best-studied being the bHLH protein INDUCER OF CBF EXPRESSION 1/SCREAM 1 (ICE1/SCRM1)

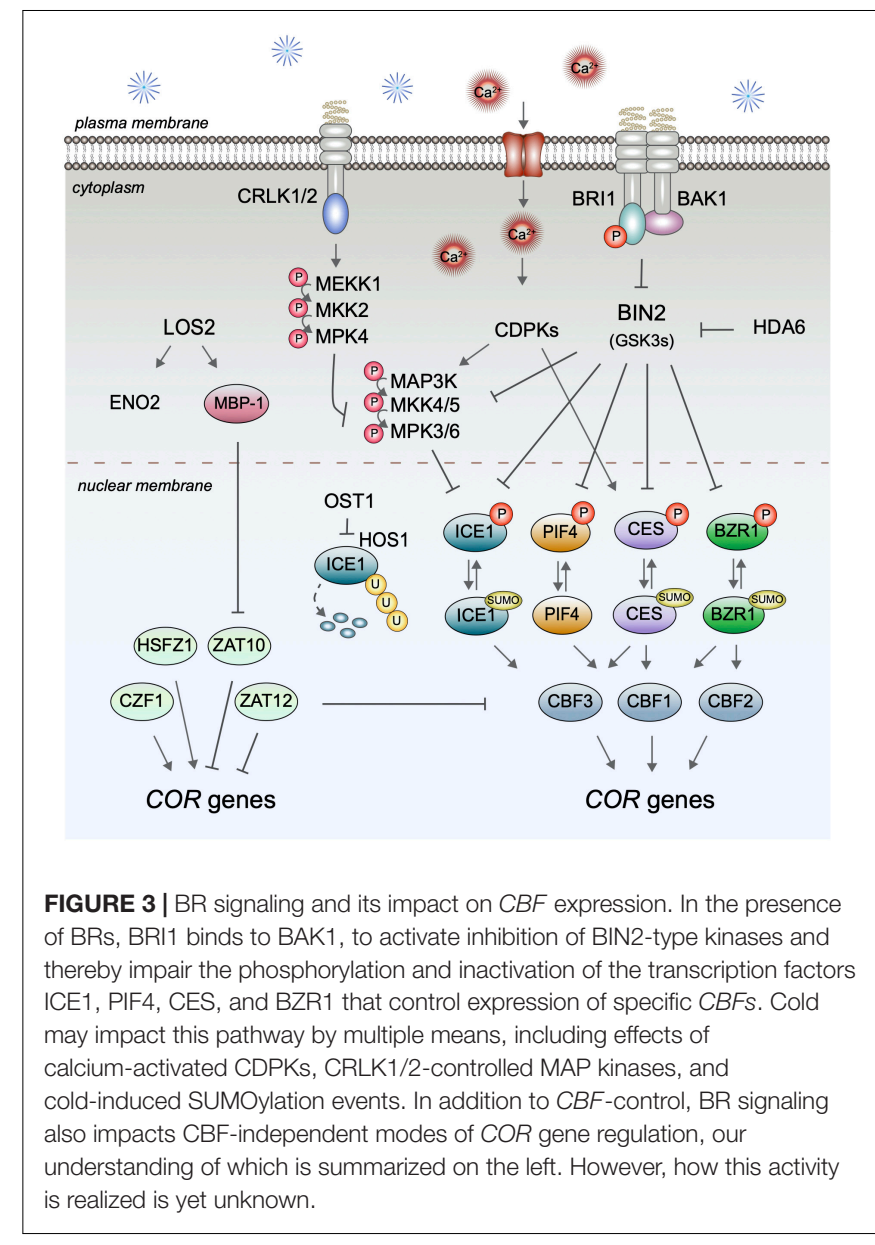

and its homolog ICE2/SCRM2, which control CBF3 abundance (Ye et al., 2019). Importantly, recently it has been shown that ICE1 is a BIN2 target (Ye et al., 2019) linking it to the BR signaling pathway. BIN2 can directly phosphorylate ICE1, which reduces ICE1 protein stability and transcriptional activity, and is thought to allow for a repression of ICE1 in later stages of cold stress responses, when, following cold-induction, $C B F$ expression requires a return to basal levels. In addition to BR signaling, BIN2 kinase activity is also controlled by acetylation catalyzed by the histone deacetylase HDA6, which is required for freezing tolerance (To et al., 2011; Hao et al., 2016), and thus HDA6 may contribute to a cold stress control of BIN2 activity with potential relevance for ICE1 and other BIN2-substrates.

In addition to ICE1, also the BR-regulated bHLH proteins CES and the BEEs take part in CBF control. CES can directly bind to the promoters of all three $\mathrm{CBFs}$ in vitro and in vivo and induce their expression (Eremina et al., 2016b). Since in ces bee 1 bee 2 bee 3 quadruple mutants the expression of $C B F 1$ and $C B F 3$, but not of $C B F 2$, was significantly repressed, it appears that the CES/BEE subfamily of bHLH proteins preferentially regulates CBF1 and CBF3 mRNAs (Eremina et al., 2016b), although redundancy in function with other bHLH proteins, or tissue-specific control, may have masked CBF2 effects in the quadruple mutant. Higher order mutant combinations with additional bHLH proteins that target CBFs will be required 
to conclusively assess the relative contribution of the different bHLH proteins to $C B F$ regulation. In this context, in addition to ICE1/2, also PIF4 and PIF7 should be considered, since both can control CBF expression (Lee and Thomashow, 2012), and PIF4 is a BIN2 target (Bernardo-García et al., 2014) that cooperates with BZR1 in transcriptional regulation (Oh E. et al., 2012).

ICE1 activity in CBF regulation is controlled by multiple upstream events with posttranslational modification being essential. The current postulation is that in response to cold stress ICE1 is phosphorylated by the ABA-regulated kinase OPEN STOMATA 1 (OST1). This inhibits ubiquitination by the UBQ E3 ligase HIGH EXPRESSION OF OSMOTICALLY RESPONSIVE GENES1 (HOS1) and degradation, resulting in ICE1 accumulation (Ding et al., 2015). Later, ICE1 is phosphorylated by the MAP kinases MPK3/6 (Zhao et al., 2017) and also by BIN2, which promotes HOS1 interaction (Ye et al., 2019), and, following ubiquitination, is degraded by the proteasome. MPK3/6 activities in cold stress responses are controlled by MKK5 and an additional unknown MAPK kinase, and adjusted by the MAPK kinase YDA and the MEKK1MKK1/2-MPK4 cascade (Li et al., 2017; Zhao et al., 2017). YDA represses MPK3/6 activities in a cold-induced manner (Zhao et al., 2017), which may enable adjustment of $C B F$ expression and repression of the pathway once $C O R$ genes have been activated and CBF removal is required (Ramirez and Poppenberger, 2017). In this context interestingly, BRs are known to impact on the YDA-MKK4/5-MPK3/6 MAP kinase module. BIN2 can phosphorylate both YDA (Kim et al., 2012) and MKK4/5 (Khan et al., 2013) and thereby repress MPK3/6 activities. As yet this cross-talk has only been shown to be relevant for stomatal patterning events (Wang and Estelle, 2014), however, clearly it will be important to assess, if it also contributes to BR function in $C B F$ transcription and freezing tolerance.

In addition to phosphorylation and ubiquitination, SUMOylation also takes part in cold stress responses. Following cold exposure, the overall SUMOylation of proteins in plants drastically increases, and it has been shown that ICE1 SUMOylation enhances its activity in CBF3 activation (Miura et al., 2007). Similarly, BZR1 and CES are SUMOylated (Khan et al., 2014; Srivastava et al., 2020) and there is evidence that SUMOylation promotes CES activity in freezing tolerance (Eremina et al., 2016b). While the upstream SUMO E3 ligase that targets CES has remained unknown, SIZ1 is a suitable candidate since SIZ1 SUMOylates ICE1 and, in addition to many other roles, is also important in freezing tolerance (Miura et al., 2007). How SUMOylation of ICE1 is induced is unclear, although a phosphorylation-deficient ICE1 mutant is more readily SUMOylated in response to cold (Miura et al., 2011). Phosphorylation also counteracts SUMOylation of CES, and there is some evidence that calcium-dependent protein kinases (CDPKs) are involved (Khan et al., 2014). CDPKs have both $\mathrm{Ca}^{2+}$ sensing and responding activities and can thereby directly translate $\mathrm{Ca}^{2+}$ signals into phosphorylation events. They are activated transiently to regulate TF activities either independently or in cross-talk with MAPK signaling cascades (Boudsocq and Sheen, 2013). CDPKs are thought to act as positive regulators of cold stress responses since cold induces expression of certain
OsCDPKs and over-expression of the OsCDPK7 in rice, thereby increasing resistance to cold, drought, and salinity (Saijo et al., 2000). Whether CDPK-mediated phosphorylation of CES or other BR-regulated TFs contribute to $C B F$ control remains to be addressed.

Another BR-regulated TF which functions in $C B F$ regulation is BZR1. BZR1 can bind to the promoters of both $C B F 1$ and $C B F 2$ and in the dominant bzr1-1D mutant CBF1 and CBF2 mRNA levels and freezing tolerance are increased. Moreover, in response to cold stress accumulation of the de-phosphorylated, active form of BZR1 was promoted (Li et al., 2017). In addition to $C B F$ regulation in basal growth conditions, there is evidence that BZR1 and the CES/BEE proteins contribute to CBF independent routes of $C O R$ gene regulation, which are much less studied today, but certainly worth a consideration.

\section{BRs in CBF-Independent Routes of COR Gene Regulation}

The low temperature regulatory network beyond the $\mathrm{CBF}$ pathways is complex and highly interconnected and although it appears to account for the majority of cold stress responses in A. thaliana (Park et al., 2015), it has remained largely unstudied. One of the only CBF-independent signaling routes elucidated in some detail today is the control of ZAT10 expression by LOS2, a bifunctional, cold-responsive locus that encodes both the TF MBP-1 and the enolase ENO2 (Lee et al., 2002; Kang et al., 2013; Eremina et al., 2015). However, neither up-stream events in LOS2 regulation by cold nor modes of ZAT10 activity in freezing tolerance are understood.

Brassinosteroids, in addition to promoting $C B F$ expression in basal conditions, also take part in CBF-independent routes of COR gene activation and this likely accounts for the major part of their function in acquired freezing tolerance. A whole-transcriptome analysis of bri1-301 plants following cold treatment identified non-CBF-regulon types of COR genes that depended on BRI1 activity. Importantly, there was a highly significant overlap of genes miss-regulated in both bri1-301 and ces bee1 bee2 bee 3 quadruple mutant plants following cold exposure, providing evidence that the role of BRs in cold acclimation is conferred to a significant degree by the CES/BEE proteins (Eremina et al., 2016b). Among the COR genes that failed to be repressed in bri1-301 and the ces bee1 bee 2 bee 3 quadruple mutant, annotations involving cell cycle regulation, cell skeleton, and microtubule activity were overrepresented. This indicates that without a functional BR-CES/BEE module, plants are unable to decrease cell division and metabolism in the cold. Additionally, annotations for fatty acid and lipid synthesis, metabolism, and transport were over-represented (Eremina et al., 2016b) and it will therefore be interesting to see, if a role of $\mathrm{CES} / \mathrm{BEEs}$ in these processes may contribute to their role in freezing tolerance.

Non-CBF-regulon targets of BZR1 include PYR1-LIKE 6 (PYL6), WRKY TF 6 (WRKY6), which play positive roles in ABA signaling, SENESCENCE-ASSOCIATED GENE 21 (SAG21), JASMONIC ACID CARBOXYL METHYLTRANSFERASE (JMT), and EPITHIOSPECIFIER MODIFIER1 (ESM1), which 
are involved in defense responses, and SUPPRESSOR OF OVEREXPRESSION OF CO 1 (SOC1), which is involved in flowering time control (Li et al., 2017). The relative contribution of $\mathrm{CES} / \mathrm{BEE}$ and BZR1 down-stream targets to BR-conferred effects in freezing tolerance remains to be tested.

\section{BRs and Cold Stress Perception}

While significant progress was made in elucidating signal transduction cascades that plants utilize to respond to cold stress, very little is still known about low temperature perception. A number of candidates for temperature sensors have been put forward and changes in membrane fluidity have been favored for some time. Membranes are the primary site of temperature perception. Their rigidification in response to cold will therefore likely impact on the activity of membrane-bound receptors, although transcriptome analysis showed no differences in COR gene expression between mutants that differed in membrane lipid saturation in A. thaliana (Knight and Knight, 2012).

Candidates of membrane-bound proteins that could serve as cold sensors are Histidine kinase Hik33, Bacillus subtilis histidine kinase DesK, and the mechanosensory $\mathrm{Ca}^{2+}$ - and $\mathrm{K}^{+}$-channels (Markovskaya and Shibaeva, 2017). Since low temperature induces a transient influx of $\mathrm{Ca}^{2+}$ ions into the cytoplasm (Kiegle et al., 2000; Knight and Knight, 2001; Scrase-Field and Knight, 2003), it is thought that calcium channels serve as multifunctional sensors (Medvedev, 2005) that sense stress-induced changes in plasma membranes, including changing fluidity. In rice, COLD1 was proposed as a cold sensor, since it was found to be essential for chilling tolerance and play a role in the activation of $\mathrm{Ca}^{2+}$ channels in response to cold stress (Ma et al., 2015). Since there is evidence that $\mathrm{BRs}$ contribute to $\mathrm{Ca}^{2+}$ influx by impacting on the activity of $\mathrm{Ca}^{2+}$-channels (Straltsova et al., 2015), it is conceivable that they could be taking part in cold perception modes, although this is another hypothesis that remains to be tested.

Another class of membrane-bound proteins, which likely contributes to the initiation of cold signaling, are calcium/calmodulin-regulated receptor-like kinases (CRLKs). In $A$. thaliana, CRLK1 and CRLK2 are required for the cold-induced induction of CBFs and act upstream of the MEKK1-MKK2-MPK4 module in the cold response pathway (Yang et al., 2010). Moreover, the COLD-RESPONSIVE PROTEIN KINASE 1 (CRPK1), which is activated by cold, was shown to phosphorylate 14-3-3 proteins that then shuttle from the cytoplasm to the nucleus to de-stabilize CBFs (Liu and Zhou, 2017). Since 14-3-3 proteins, through effects on BZR1 (Gampala et al., 2007) and BKI1 (Wang et al., 2011), are also involved in BR signaling in ambient conditions, it will be interesting to see if 14-3-3 proteins may also impact on BR activity in cold stress responses.

\section{ENVIRONMENTAL IMPACT ON BR FUNCTION IN COLD STRESS RESPONSES}

Temperature perception and signaling is strongly impacted by other environmental cues and also by intrinsic developmental programs. In particular, light is known to play an essential role in cold stress responses. Light is required for full cold acclimation (Wanner and Junttila, 1999) and induction of CBF expression (Kim et al., 2002; Soitama et al., 2008). A low red to far-red light ratio can increase $C B F$ expression in a circadian-clock controlled manner even in the absence of cold, which is sufficient to improve freezing tolerance in A. thaliana (Franklin and Whitelam, 2007). In particular, the phytochrome light receptors PHYB and PHYD appear to be important in $C B F$ regulation since in $p h y B$ and $p y h D$ mutants the CBF-regulon is constitutively induced in A. thaliana (Franklin and Whitelam, 2007), tomato (Wang et al., 2016), and rice (He et al., 2017). Because PHYB regulates activity of PIF4 and PIF7, both of which are able to repress $C B F$ expression in long-days (Lee and Thomashow, 2012), and PIF4 activity is also induced by BRs (Bernardo-García et al., 2014), there are indications for an interplay of light, cold, and BR signaling in $C B F$ transcription. It remains to be tested, if this potential interplay may be mediated by a cooperation of BZR1 with PIF4, which as yet has only been shown to be relevant for growth control at ambient and high temperatures (Oh E. et al., 2012; Ibañez et al., 2018). Since light can also impact CBF-independent modes of cold stress responses (Lee et al., 2002), it is evident that much remains to be discovered about the complex cross-talk of light and cold stress responses in plants.

\section{CONCLUDING REMARKS}

In the last few years, notable progress has been made in our understanding of the exceptional capacities of BRs to promote both growth and cold stress responses. It appears that in contrast to other growth-promoting hormones such as the GAs, BRs have the capability to uncouple tolerance to cold stress, and related abiotic stress types, from trade-offs in terms of growth and yield. This may be executed, at least in part, by the ability of BRs to promote $C B F$ expression (Eremina et al., 2016b; Li et al., 2017) and to promote GA biosynthesis and signaling (Tong and Chu, 2016; Unterholzner et al., 2016) at the same time, which could release the repressive activity of $\mathrm{CBF}$ on GA activity in growth induction. However, in addition to CBF-dependent effects, it is clear that BRs also act by CBFindependent modes. Moreover, in addition to controlling TF activities, BRs may also impact upstream events including cold perception and down-stream events in physiological responses and morphological adaptations. It will be exciting to discover how these effects are realized, and explore if they can be utilized for improvements in crop production when cold stress occurs.

\section{AUTHOR CONTRIBUTIONS}

VR and BP contributed equally to all aspects of this work. Both authors contributed to the article and approved the submitted version. 


\section{FUNDING}

This work was supported by funds from the Bundesministerium für Ernährung und Landwirtschaft (BMEL; InnoSun).

\section{REFERENCES}

Achard, P., Cheng, H., De Grauwe, L., Decat, J., Schoutteten, H., Moritz, T., et al. (2006). Integration of plant responses to environmentally activated phytohormonal signals. Science 311, 91-94. doi: 10.1126/science.1118642

Achard, P., Gong, F., Cheminant, S., Alioua, M., Hedden, P., and Genschik, P. (2008). The cold-inducible CBF1 factor-dependent signaling pathway modulates the accumulation of the growth-repressing DELLA proteins via its effect on gibberellin metabolism. Plant Cell 20, 2117-2129. doi: 10.1105/tpc.108. 058941

Aghdam, M. S., Asghari, M., Farmani, B., Mohayeji, M., and Moradbeygi, H. (2012). Impact of postharvest brassinosteroids treatment on PAL activity in tomato fruit in response to chilling stress. Sci. Hortic. 144, 116-120. doi: 10. 1016/j.scienta.2012.07.008

Albertos, P., Wagner, K., and Poppenberger, B. (2019). Cold stress signalling in female reproductive tissues. Plant Cell Environ. 42, 846-853. doi: 10.1111/pce. 13408

Allen, D. J., and Ort, D. R. (2001). Impacts of chilling temperatures on photosynthesis in warm-climate plants. Trends Plant Sci. 6, 36-42. doi: 10.1016/ S1360-1385(00)01808-2

Augspurger, C. K. (2013). Reconstructing patterns of temperature, phenology, and frost damage over 124 years: spring damage risk is increasing. Ecology 94, 41-50. doi: 10.1890/12-0200.1

Bajguz, A., and Hayat, S. (2009). Effects of brassinosteroids on the plant responses to environmental stresses. Plant Physiol. Biochem. 47, 1-8. doi: 10.1016/j. plaphy.2008.10.002

Bao, Y., and Howell, S. H. (2017). The unfolded protein response supports plant development and defense as well as responses to abiotic stress. Front. Plant Sci. 8:344. doi: 10.3389/fpls.2017.00344

Benatti, M. R., Penning, B. W., Carpita, N. C., and McCann, M. C. (2012). We are good to grow: dynamic integration of cell wall architecture with the machinery of growth. Front. Plant Sci. 3:187. doi: 10.3389/Fpls.2012.00187

Bernardo-García, S., de Lucas, M., Martínez, C., Espinosa-Ruiz, A., Davière, J. M., and Prat, S. (2014). BR-dependent phosphorylation modulates PIF4 transcriptional activity and shapes diurnal hypocotyl growth. Genes Dev. 28, 1681-1694. doi: 10.1101/gad.243675.114

Boudsocq, M., and Sheen, J. (2013). CDPKs in immune and stress signaling. Trends Plant Sci. 18, 30-40. doi: 10.1016/j.tplants.2012.08.008

Buchanan, B. B., Gruissem, W., and Jones, R. L. (2000). Biochem. Mol Biol. Plants. 40. Rockville, MD: American Society of Plant Physiologists. doi: 10.1023/A: 1013849028622

Che, P., Bussell, J. D., Zhou, W., Estavillo, G. M., Pogson, B. J., and Smith, S. M. (2010). Signaling from the endoplasmic reticulum activates brassinosteroid signaling and promotes acclimation to stress in Arabidopsis. Sci. Signal. 3:69. doi: $10.1126 /$ scisignal.2001140

Chmielewski, F.-M., Müller, A., and Bruns, E. (2004). Climate changes and trends in phenology of fruit trees and field crops in Germany, 1961-2000. Agricult. Forest. Meterol. 121, 69-78. doi: 10.1016/s0168-1923(03)00161-8

Choudhury, F. K., Rivero, R. M., Blumwald, E., and Mittler, R. (2017). Reactive oxygen species, abiotic stress and stress combination. Plant J. 90, 856-867. doi: $10.1111 /$ tpj.13299

Clouse, S. D. (2002). Arabidopsis mutants reveal multiple roles for sterols in plant development. Plant Cell 14, 1995-2000. doi: 10.1105/tpc.140930

Clouse, S. D. (2011). Brassinosteroid signal transduction: from receptor kinase activation to transcriptional networks regulating plant development. Plant Cell 23, 1219-1230. doi: 10.1105/tpc.111.084475

Ding, Y., Li, H., Zhang, X., Xie, Q., Gong, Z., and Yang, S. (2015). OST1 kinase modulates freezing tolerance by enhancing ICE1 stability in Arabidopsis. Dev. Cell 32, 278-289. doi: 10.1016/j.devcel.2014.12.023

\section{ACKNOWLEDGMENTS}

We apologize to all colleagues whose contributions could not be cited or discussed due to space limitations. VR is a member of the TUM graduate school.

Divi, U. K., and Krishna, P. (2009). Brassinosteroid: a biotechnological target for enhancing crop yield and stress tolerance. N. Biotechnol. 26, 131-136. doi: 10.1016/j.nbt.2009.07.006

Du, L., and Poovaiah, B. W. (2005). Ca 2+/calmodulin is critical for brassinosteroid biosynthesis and plant growth. Nature 437, 741-745. doi: 10.1038/nature03973

Eremina, M., Rozhon, W., and Poppenberger, B. (2016a). Hormonal control of cold stress responses in plants. Cell. Mol. Life Sci. 73, 797-810. doi: 10.1007/s00018015-2089-6

Eremina, M., Rozhon, W., Yang, S., and Poppenberger, B. (2015). ENO 2 activity is required for the development and reproductive success of plants, and is feedback-repressed by A t MBP-1. Plant J. 81, 895-906. doi: 10.1111/tpj.12775

Eremina, M., Unterholzner, S. J., Rathnayake, A. I., Castellanos, M., Khan, M., Kugler, K. G., et al. (2016b). Brassinosteroids participate in the control of basal and acquired freezing tolerance of plants. Proc. Natl. Acad. Sci. U.S.A. 113, E5982-E5991. doi: 10.1073/pnas.1611477113

Francis, J. A., and Vavrus, S. J. (2012). Evidence linking Arctic amplification to extreme weather in mid-latitudes. Geophys. Res. Lett. 39:L06801. doi: 10.1029/ 2012GL051000

Franklin, K. A., and Whitelam, G. C. (2007). Light-quality regulation of freezing tolerance in Arabidopsis thaliana. Nat. Genet. 39:1410. doi: 10.1038/ng.2007.3

Gampala, S. S., Kim, T. W., He, J. X., Tang, W., Deng, Z., Bai, M. Y., et al. (2007). An essential role for 14-3-3 proteins in brassinosteroid signal transduction in Arabidopsis. Dev. Cell 13, 177-189. doi: 10.1016/j.devcel.2007.0 6.009

Goda, H., Shimada, Y., Asami, T., Fujioka, S., and Yoshida, S. (2002). Microarray analysis of brassinosteroid-regulated genes in Arabidopsis. Plant Phys. 130, 1319-1334. doi: 10.1104/pp.011254

Gururani, M. A., Venkatesh, J., and Tran, L. S. P. (2015). Regulation of photosynthesis during abiotic stress-induced photoinhibition. Mol. Plant 8, 1304-1320. doi: 10.1016/j.molp.2015.05.005

Hao, Y., Wang, H., Qiao, S., Leng, L., and Wang, X. (2016). Histone deacetylase HDA6 enhances brassinosteroid signaling by inhibiting the BIN2 kinase. Proc. Natl. Acad. Sci. U.S.A. 113, 10418-10423. doi: 10.1073/pnas.1521363113

Hatfield, J. L., and Prueger, J. H. (2015). Temperature extremes: effect on plant growth and development. Weather. Clim. Extremes 10, 4-10. doi: 10.1016/j. wace.2015.08.001

He, R. Y., Wang, G. J., and Wang, X. S. (1991). Effects of brassinolide on growth and chilling resistance of maize seedlings. ACS Symposium Series 474, 220-230. doi: 10.1021/bk-1991-0474.ch019

He, X. L., Fan, S. K., Zhu, J., Guan, M. Y., Liu, X. X., Zhang, Y. S., et al. (2017). Iron supply prevents Cd uptake in Arabidopsis by inhibiting IRT1 expression and favoring competition between Fe and Cd uptake. Plant. Soil 416, 453-462. doi: 10.1007/s11104-017-3232-y

Hossain, Z., McGarvey, B., Amyot, L., Gruber, M., Jung, J., and Hannoufa, A. (2012). DIMINUTO 1 affects the lignin profile and secondary cell wall formation in Arabidopsis. Planta 235, 485-498. doi: 10.1007/s00425-011-1519-4

Hu, Y., Wu, Q., Sprague, S. A., Park, J., Oh, M., Rajashekar, C. B., et al. (2015). Tomato expressing Arabidopsis glutaredoxin gene AtGRXS17 confers tolerance to chilling stress via modulating cold responsive components. Hort. Res. 2:15051. doi: 10.1038/hortres.2015.51

Ibañez, C., Delker, C., Martinez, C., Bürstenbinder, K., Janitza, P., Lippmann, R., et al. (2018). Brassinosteroids dominate hormonal regulation of plant thermomorphogenesis via BZR1. Curr. Biol. 28, 303-310. doi: 10.1016/j.cub. 2017.11.077

Ingram, J., and Bartels, D. (1996). The molecular basis of dehydration tolerance in plants. Annu. Rev. Plant Biol. 47, 377-403. doi: 10.1146/annurev.arplant.47. 1.377

Jaglo-Ottosen, K. R., Gilmour, S. J., Zarka, D. G., Schabenberger, O., and Thomashow, M. F. (1998). Arabidopsis CBF1 overexpression induces COR 
genes and enhances freezing tolerance. Science 280, 104-106. doi: 10.1126/ science.280.5360.104

Janská, A., Maršík, P., Zelenková, S., and Ovesná, J. (2010). Cold stress and acclimation-what is important for metabolic adjustment? Plant Biol. 12, 395405. doi: 10.1111/j.1438-8677.2009.00299.x

Kagale, S., Divi, U. K., Krochko, J. E., Keller, W. A., and Krishna, P. (2007). Brassinosteroid confers tolerance in Arabidopsis thaliana and Brassica napus to a range of abiotic stresses. Planta 225, 353-364. doi: 10.1007/s00425-0060361-6

Kang, M., Abdelmageed, H., Lee, S., Reichert, A., Mysore, K. S., and Allen, R. D. (2013). At MBP-1, an alternative translation product of LOS 2, affects abscisic acid responses and is modulated by the E 3 ubiquitin ligase A t SAP 5. Plant J. 76, 481-493. doi: 10.1111/tpj.12312

Karkonen, A., and Koutaniemi, S. (2010). Lignin biosynthesis studies in plant tissue cultures. J. Integr. Plant Biol. 52, 176-185. doi: 10.1111/j.1744-7909.2010. 00913.x

Katsumi, M. (1991). Physiological modes of brassinolide action in cucumber hypocotyl growth. ACS Symposium Series 474, 246-254. doi: 10.1021/bk-19910474.ch021

Khan, M., Rozhon, W., Bigeard, J., Pflieger, D., Husar, S., Pitzschke, A., et al. (2013). Brassinosteroid-regulated GSK3/Shaggy-like kinases phosphorylate mitogenactivated protein (MAP) kinase kinases, which control stomata development in Arabidopsis thaliana. J. Biol. Chem. 288, 7519-7527. doi: 10.1074/jbc.M112. 384453

Khan, M., Rozhon, W., Unterholzner, S. J., Chen, T., Eremina, M., Wurzinger, B., et al. (2014). Interplay between phosphorylation and SUMOylation events determines CESTA protein fate in brassinosteroid signalling. Nat. Commun. 5 , 1-10. doi: 10.1038/ncomms5687

Kiegle, E., Moore, C. A., Haseloff, J., Tester, M. A., and Knight, M. R. (2000). Cell-type-specific calcium responses to drought, salt and cold in the Arabidopsis root. Plant J. 23, 267-278. doi: 10.1046/j.1365-313x.2000. 00786.x

Kim, H. J., Kim, Y. K., Park, J. Y., and Kim, J. (2002). Light signalling mediated by phytochrome plays an important role in cold-induced gene expression through the C-repeat/dehydration responsive element (C/DRE) in Arabidopsis thaliana. Plant J. 29, 693-704. doi: 10.1046/j.1365-313X.2002. 01249.x

Kim, S. Y., Kim, B. H., Lim, C. J., Lim, C. O., and Nam, K. H. (2010). Constitutive activation of stress-inducible genes in a brassinosteroid-insensitive 1 (bri1) mutant results in higher tolerance to cold. Physiologia plantarum, 138, 191-204. doi: 10.1111/j.1399-3054.2009.01304.x

Kim, T. W., Michniewicz, M., Bergmann, D. C., and Wang, Z. Y. (2012). Brassinosteroid regulates stomatal development by GSK3-mediated inhibition of a MAPK pathway. Nature 482:419. doi: 10.1038/nature10794

Kim, T. W., and Wang, Z. Y. (2010). Brassinosteroid signal transduction from receptor kinases to transcription factors. Annu. Rev. Plant Biol. 61, 681-704. doi: 10.1146/annurev.arplant.043008.092057

Klotke, J., Kopka, J., Gatzke, N., and Heyer, A. G. (2004). Impact of soluble sugar concentrations on the acquisition of freezing tolerance in accessions of Arabidopsis thaliana with contrasting cold adaptation-evidence for a role of raffinose in cold acclimation. Plant Cell. Environ. 27, 1395-1404. doi: 10.1111/j. 1365-3040.2004.01242.x

Knaupp, M., Mishra, K. B., Nedbal, L., and Heyer, A. G. (2011). Evidence for a role of raffinose in stabilizing photosystem II during freeze-thaw cycles. Planta 234, 477-486. doi: 10.1007/s00425-011-1413-0

Knight, H., and Knight, M. R. (2001). Abiotic stress signalling pathways: specificity and cross-talk. Trends Plant Sci. 6, 262-267. doi: 10.1016/S1360-1385(01) 01946-X

Knight, M. R., and Knight, H. (2012). Low-temperature perception leading to gene expression and cold tolerance in higher plants. New Phytol. 195, 737-751. doi: 10.1111/j.1469-8137.2012.04239.x

Koh, S., Lee, S. C., Kim, M. K., Koh, J. H., Lee, S., An, G., et al. (2007). T-DNA tagged knockout mutation of rice OsGSK1, an orthologue of Arabidopsis BIN2, with enhanced tolerance to various abiotic stresses. Plant Mol. Biol. 65, 453-466. doi: 10.1007/s11103-007-9213-4

Kumar, M., Campbell, L., and Turner, S. (2015). Secondary cell walls: biosynthesis and manipulation. J. Exp. Bot. 67, 515-531. doi: 10.1093/jxb/ erv533
Le Gall, H., Philippe, F., Domon, J. M., Gillet, F., Pelloux, J., and Rayon, C. (2015). Cell wall metabolism in response to abiotic stress. Plants 4, 112-166. doi: $10.3390 /$ plants 4010112

Lee, C. M., and Thomashow, M. F. (2012). Photoperiodic regulation of the C-repeat binding factor (CBF) cold acclimation pathway and freezing tolerance in Arabidopsis thaliana. Proc. Natl. Acad. Sci. U.S.A. 109, 15054-15059. doi: 10.1073/pnas.1211295109

Lee, H., Guo, Y., Ohta, M., Xiong, L., Stevenson, B., and Zhu, J. K. (2002). LOS2, a genetic locus required for cold-responsive gene transcription encodes a bi-functional enolase. EMBO J. 21, 2692-2702. doi: 10.1093/emboj/21.11. 2692

Li, M., Ahammed, G. J., Li, C., Bao, X., Yu, J., Huang, C., et al. (2016). Brassinosteroid ameliorates zinc oxide nanoparticles-induced oxidative stress by improving antioxidant potential and redox homeostasis in tomato seedling. Front. Plant Sci. 7, 615. doi: 10.3389/fpls.2016.00615

Li, C., Zhang, S., and Wang, X. (2017). Novel signaling interface constituted with membrane receptor-like kinases emerged from the study of interaction and transphosphorylation of BRI1 and BAK1. Curr. Top. Med. Chem. 17, 2393-2400. doi: 10.2174/1568026617666170414144145

Lindow, S. E., Arny, D. C., and Upper, C. D. (1982). Bacterial ice nucleation: a factor in frost injury to plants. Plant Physiol. 70, 1084-1089. doi: 10.1104/pp.70.4.1084

Lissarre, M., Ohta, M., Sato, A., and Miura, K. (2014). Cold-responsive gene regulation during cold acclimation in plants. Plant Signal. Behav. 5, 948-952. doi: $10.4161 /$ psb.5.8.12135

Liu, Y., Zhao, Z., Si, J., Di, C., Han, J., and An, L. (2009). Brassinosteroids alleviate chilling-induced oxidative damage by enhancing antioxidant defense system in suspension cultured cells of Chorispora bungeana. Plant Growth Regul. 59, 207-214. doi: 10.1007/s10725-009-9405-9

Liu, Y., and Zhou, J. (2017). MAPping kinase regulation of ICE1 in freezing tolerance. Trends Plant. Sci. 23, 91-93. doi: 10.1016/j.tplants.2017.12.002

Lv, M., and Li, J. (2020). Molecular mechanisms of brassinosteroid-mediated responses to changing environments in Arabidopsis. Int. J. Mol. Sci. 21, 2737. doi: 10.3390/ijms21082737

Ma, Y., Dai, X., Xu, Y., Luo, W., Zheng, X., Zeng, D., et al. (2015). COLD1 confers chilling tolerance in rice. Cell 160, 1209-1221. doi: 10.1016/j.cell.2015.0 1.046

Magome, H., Yamaguchi, S., Hanada, A., Kamiya, Y., and Oda, K. (2008). The DDF1 transcriptional activator upregulates expression of a gibberellindeactivating gene, GA2ox7, under high-salinity stress in Arabidopsis. Plant J. 56, 613-626. doi: 10.1111/j.1365-313X.2008.03627.x

Marcos, R., Izquierdo, Y., Vellosillo, T., Kulasekaran, S., Cascón, T., Hamberg, M., et al. (2015). 9-Lipoxygenase-derived oxylipins activate brassinosteroid signaling to promote cell wall-based defense and limit pathogen infection. Plant Physiol. 169, 2324-2334. doi: 10.1104/pp.15.00992

Markovskaya, E. F., and Shibaeva, T. G. (2017). Low temperature sensors in plants: hypotheses and assumptions. Biol. Bull. Rev. 44, 150-158. doi: 10.1134/ S1062359017020145

Medvedev, S. S. (2005). Calcium signaling system in plants. Russ. J. Plant Physiol. 52, 249-270. doi: 10.1007/s11183-005-0038-1

Mittler, R. (2002). Oxidative stress, antioxidants and stress tolerance. Trends Plant Sci. 7, 405-410. doi: 10.1016/S1360-1385(02)02312-9

Mittler, R. (2006). Abiotic stress, the field environment and stress combination. Trends Plant Sci. 11, 15-19. doi: 10.1016/j.tplants.2005.11.002

Mittler, R., Vanderauwera, S., Gollery, M., and Van Breusegem, F. (2004). Reactive oxygen gene network of plants. Trends Plant Sci. 9, 490-498. doi: 10.1016/j. tplants.2004.08.009

Miura, K., Jin, J. B., Lee, J., Yoo, C. Y., Stirm, V., Miura, T., et al. (2007). SIZ1mediated sumoylation of ICE1 controls CBF3/DREB1A expression and freezing tolerance in Arabidopsis. Plant Cell 19, 1403-1414. doi: 10.1105/tpc.106.048397

Miura, K., Ohta, M., Nakazawa, M., Ono, M., and Hasegawa, P. M. (2011). ICE1 Ser403 is necessary for protein stabilization and regulation of cold signaling and tolerance. Plant J. 67, 269-279. doi: 10.1111/j.1365-313X.2011.04589.x

Morel, J. B., and Dangl, J. L. (1997). The hypersensitive response and the induction of cell death in plants. Cell Death Differ. 4:671. doi: 10.1038/sj.cdd.4400309

Nishiyama, I. (1995). Damage due to extreme temperatures. Rice Sci. 2, 769-812.

Nolan, T. M., Vukašinovć, N., Liu, D., Russinova, E., and Yin, Y. (2020). Brassinosteroids: Multidimensional regulators of plant growth, development, and stress responses. Plant Cell, 32, 295-318. doi: 10.1105/tpc.19.00335 
Oh, E., Zhu, J. Y., and Wang, Z. Y. (2012). Interaction between BZR1 and PIF4 integrates brassinosteroid and environmental responses. Nature Cell Biol. 14:802. doi: $10.1038 /$ ncb2545

Oh, M. H., Kim, H. S., Wu, X., Clouse, S. D., Zielinski, R. E., and Huber, S. C. (2012). Calcium/calmodulin inhibition of the Arabidopsis BRASSINOSTEROIDINSENSITIVE 1 receptor kinase provides a possible link between calcium and brassinosteroid signalling. Biochem. J. 443, 515-523. doi: 10.1042/BJ20111871

Oh, M. H., Wang, X., Kota, U., Goshe, M. B., Clouse, S. D., and Huber, S. C. (2009). Tyrosine phosphorylation of the BRI1 receptor kinase emerges as a component of brassinosteroid signaling in Arabidopsis. Proc. Natl. Acad. Sci. U.S.A. 106, 658-663. doi: 10.1073/pnas.0810249106

Ohashi-Ito, K., Oda, Y., and Fukuda, H. (2010). Arabidopsis VASCULARRELATED NAC-DOMAIN6 directly regulates the genes that govern programmed cell death and secondary wall formation during xylem differentiation. Plant Cell 22, 3461-3473. doi: 10.1105/tpc.110.075036

Oldroyd, G. E., and Downie, J. A. (2004). Calcium, kinases and nodulation signalling in legumes. Nat. Rev. Mol. Cell. Biol. 5, 566-576. doi: 10.1038/ nrm 1424

Pagter, M., Alpers, J., Erban, A., Kopka, J., Zuther, E., and Hincha, D. K. (2017). Rapid transcriptional and metabolic regulation of the deacclimation process in cold acclimated Arabidopsis thaliana. BMC Genomics, 18, 731. doi: 10.1186/ s12864-017-4126-3

Park, S., Lee, C. M., Doherty, C. J., Gilmour, S. J., Kim, Y., and Thomashow, M. F. (2015). Regulation of the Arabidopsis CBF regulon by a complex lowtemperature regulatory network. Plant J. 82, 193-207. doi: 10.1111/tpj.12796

Petridis, A., Döll, S., Nichelmann, L., Bilger, W., and Mock, H. P. (2016). Arabidopsis thaliana G2-LIKE FLAVONOID REGULATOR and BRASSINOSTEROID ENHANCED EXPRESSION1 are low-temperature regulators of flavonoid accumulation. New Phytol. 211, 912-925. doi: $10.1111 /$ nph. 13986

Planas-Riverola, A., Gupta, A., Betegón-Putze, I., Bosch, N., Ibañes, M., and CañoDelgado, A. I. (2019). Brassinosteroid signaling in plant development and adaptation to stress. Development, 146. doi: 10.1242/dev.151894

Ramirez, V. E., and Poppenberger, B. (2017). MAP kinase signaling turns to ICE. Dev. Cell 43, 545-546. doi: 10.1016/j.devcel.2017.10.032

Rao, X., and Dixon, R. A. (2017). Brassinosteroid mediated cell wall remodeling in grasses under abiotic stress. Front. Plant Sci. 8:806. doi: 10.3389/fpls.2017. 00806

Rapacz, M., Jurczyk, B., and Sasal, M. (2017). Deacclimation may be crucial for winter survival of cereals under warming climate. Plant Sci. 256, 5-15. doi: 10.1016/j.plantsci.2016.11.007

Rigby, J. R., and Porporato, A. (2008). Spring frost risk in a changing climate. Geophys. Res. Let. 35:L12703. doi: 10.1029/2008gl033955

Ruelland, E., Vaultier, M. N., Zachowski, A., and Hurry, V. (2009). Cold signalling and cold acclimation in plants. Adv. Bot. Res. 49, 35-150. doi: 10.1016/S00652296(08)00602-2

Saijo, Y., Hata, S., Kyozuka, J., Shimamoto, K., and Izui, K. (2000). Over-expression of a single Ca2+-dependent protein kinase confers both cold and salt/drought tolerance on rice plants. Plant J. 23, 319-327. doi: 10.1046/j.1365-313x.2000. 00787.x

Scrase-Field, S. A., and Knight, M. R. (2003). Calcium: just a chemical switch? Curr. Opin. Plant Biol. 6, 500-506. doi: 10.1016/S1369-5266(03)00091-8

Shinozaki, K., Yamaguchi-Shinozaki, K., and Seki, M. (2003). Regulatory network of gene expression in the drought and cold stress responses. Curr. Opin. Plant Biol. 6, 410-417. doi: 10.1016/S1369-5266(03)00092-X

Soitama, A. J., Piippo, M., Allahverdiyea, Y., Battchikova, N., and Aro, E. M. (2008). Light has a specific role in modulating Arabidopsis gene expression at low temperature. BMC Plant Biol. 8:13. doi: 10.1186/1471-2229-8-13

Srivastava, M., Srivastava, A. K., Orosa-Puente, B., Campanaro, A., Zhang, C., and Sadanandom, A. (2020). SUMO conjugation to BZR1 enables brassinosteroid signaling to integrate environmental cues to shape plant growth. Curr. Biol. 30:1423.e3. doi: 10.1016/j.cub.2020.01.089

Straltsova, D., Chykun, P., Subramaniam, S., Sosan, A., Kolbanov, D., Sokolik, A., et al. (2015). Cation channels are involved in brassinosteroid signalling in higher plants. Steroids 97, 98-106. doi: 10.1016/j.steroids.2014. 10.008

Taiz, L., Zeiger, E., Moller, I. M., and Murphy, A. (2015). Plant Physiology and Development, 6th Edn. Sunderland, CT: Sinauer Associates.
Tasseva, G., Richard, L., and Zachowski, A. (2004). Regulation of phosphatidylcholine biosynthesis under salt stress involves choline kinases in Arabidopsis thaliana. FEBS Lett. 566, 115-120. doi: 10.1016/j.febslet.2004. 04.015

Tenhaken, R. (2015). Cell wall remodeling under abiotic stress. Front. Plant Sci. 5:771. doi: 10.3389/fpls.2014.00771

Thakur, P., Kumar, S., Malik, J. A., Berger, J. D., and Nayyar, H. (2010). Cold stress effects on reproductive development in grain crops: an overview. Environ. Exp. Bot. 67, 429-443. doi: 10.1016/j.envexpbot.2009.09.004

Thomashow, M. F. (1999). Plant cold acclimation: freezing tolerance genes and regulatory mechanisms. Annu. Rev. Plant Biol. 50, 571-599. doi: 10.1146/ annurev.arplant.50.1.571

Tjus, S. E., Scheller, H. V., Andersson, B., and Møller, B. L. (2001). Active oxygen produced during selective excitation of photosystem I is damaging not only to photosystem I, but also to photosystem II. Plant Physiol. 125, 2007-2015. doi: $10.1104 /$ pp.125.4.2007

To, T. K., Nakaminami, K., Kim, J. M., Morosawa, T., Ishida, J., Tanaka, M., et al. (2011). Arabidopsis HDA6 is required for freezing tolerance. Biochem. Biophys. Res. Commun. 406, 414-419. doi: 10.1016/j.bbrc.2011.02.058

Tong, H., and Chu, C. (2016). Reply: brassinosteroid regulates gibberellin synthesis to promote cell elongation in rice: critical comments on Ross and Quittenden's letter. Plant Cell 28, 833-835. doi: 10.1105/tpc.16.00123

Tong, H., Xiao, Y., Liu, D., Gao, S., Liu, L., Yin, Y., et al. (2014). Brassinosteroid regulates cell elongation by modulating gibberellin metabolism in rice. Plant Cell 26, 4376-4393. doi: 10.1105/tpc.114.132092

Unterholzner, S. J., Rozhon, W., Papacek, M., Ciomas, J., Lange, T., Kugler, K. G., et al. (2015). Brassinosteroids are master regulators of gibberellin biosynthesis in Arabidopsis. Plant Cell 27, 2261-2272. doi: 10.1105/tpc.15.00433

Unterholzner, S. J., Rozhon, W., and Poppenberger, B. (2016). Reply: interaction between Brassinosteroids and Gibberellins: synthesis or signaling? In Arabidopsis, Both! Plant Cell 28, 836-839. doi: 10.1105/tpc.16.00120

Uozu, S., Tanaka-Ueguchi, M., Kitano, H., Hattori, K., and Matsuoka, M. (2000). Characterization of XET-related genes of rice. Plant Physiol. 122, 853-859. doi: 10.1104/Pp.122.3.853

Verslues, P. E., Agarwal, M., Katiyar-Agarwal, S., Zhu, J., and Zhu, J. K. (2006). Methods and concepts in quantifying resistance to drought, salt and freezing, abiotic stresses that affect plant water status. Plant J. 45, 523-539. doi: 10.1111/ j.1365-313X.2005.02593.x

Voxeur, A., and Hofte, H. (2016). Cell wall integrity signaling in plants: “To grow or not to grow that's the question". Glycobiology 26, 950-960. doi: 10.1093/glycob/ cww029

Vriet, C., Russinova, E., and Reuzeau, C. (2012). Boosting crop yields with plant steroids. Plant Cell 24, 842-857. doi: 10.1105/tpc.111.094912

Vyse, K., Pagter, M., Zuther, E., and Hincha, D. K. (2019). Deacclimation after cold acclimation-a crucial, but widely neglected part of plant winter survival. J. Exp. Bot. 70, 4595-4604. doi: 10.1093/jxb/erz229

Wang, H., Wang, H., Shao, H., and Tang, X. (2016). Recent advances in utilizing transcription factors to improve plant abiotic stress tolerance by transgenic technology. Front. Plant Sci. 7:67. doi: 10.3389/fpls.2016.00067

Wang, H., Yang, C., Zhang, C., Wang, N., Lu, D., Wang, J., et al. (2011). Dual role of BKI1 and 14-3-3 s in brassinosteroid signaling to link receptor with transcription factors. Dev. Cell 21, 825-834. doi: 10.1016/j.devcel.2011. 08.018

Wang, R., and Estelle, M. (2014). Diversity and specificity: auxin perception and signaling through the TIR1/AFB pathway. Curr. Opin. Plant. Biol. 21, 51-58. doi: 10.1016/j.pbi.2014.06.006

Wang, Z. Y., Nakano, T., Gendron, J., He, J., Chen, M., Vafeados, D., et al. (2002). Nuclear-localized BZR1 mediates brassinosteroid-induced growth and feedback suppression of brassinosteroid biosynthesis. Dev. Cell 2, 505-513. doi: 10.1016/s1534-5807(02)00153-3

Wanner, L. A., and Junttila, O. (1999). Cold-induced freezing tolerance in Arabidopsis. Plant Physiol. 120, 391-400. doi: 10.1104/pp.120.2.391

White, G. F., and Haas, J. E. (1975). Assessment of Research on Natural Hazards. Cambridge, MA: MIT Press.

Wolf, S., Van Der Does, D., Ladwig, F., Sticht, C., Kolbeck, A., Schürholz, A. K., et al. (2014). A receptor-like protein mediates the response to pectin modification by activating brassinosteroid signaling. Proc. Natl. Acad. Sci. U.S.A. 111, 15261-15266. doi: 10.1073/pnas.1322979111 
Xia, X. J., Fang, P. P., Guo, X., Qian, X. J., Zhou, J., Shi, K., et al. (2018). Brassinosteroid-mediated apoplastic $\mathrm{H} 2 \mathrm{O} 2$-glutaredoxin 12/14 cascade regulates antioxidant capacity in response to chilling in tomato. Plant Cell Environ. 41, 1052-1064. doi: 10.1111/pce.13052

Xia, X. J., Wang, Y. J., Zhou, Y. H., Tao, Y., Mao, W. H., Shi, K., et al. (2009). Reactive oxygen species are involved in brassinosteroid-induced stress tolerance in cucumber. Plant Physiol. 150, 801-814. doi: 10.1104/pp.109.138230

Xia, X. J., Zhou, Y. H., Shi, K., Zhou, J., Foyer, C. H., and Yu, J. Q. (2015). Interplay between reactive oxygen species and hormones in the control of plant development and stress tolerance. J. Exp. Bot. 66, 2839-2856. doi: 10.1093/jxb/ erv089

Yamada, T., Kuroda, K., Jitsuyama, Y., Takezawa, D., Arakawa, K., and Fujikawa, S. (2002). Roles of the plasma membrane and the cell wall in the responses of plant cells to freezing. Planta 215, 770-778. doi: 10.1007/s00425-002-0814-5

Yang, J. H., and Wang, H. (2016). Molecular mechanisms for vascular development and secondary cell wall formation. Front. Plant Sci. 7:356. doi: 10.3389/fpls. 2016.00356

Yang, T., Shad Ali, G., Yang, L., Du, L., Reddy, A. S. N., and Poovaiah, B. W. (2010). Calcium/calmodulin-regulated receptor-like kinase CRLK1 interacts with MEKK1 in plants. Plant Signal. Behav. 5, 991-994. doi: 10.4161/psb.5.8. 12225

Ye, K., Li, H., Ding, Y., Shi, Y., Song, C., Gong, Z., et al. (2019). BRASSINOSTEROID-INSENSITIVE2 negatively regulates the stability of transcription factor ICE1 in response to cold stress in Arabidopsis. Plant Cell 31, 2682-2696. doi: 10.1105/tpc.19.00058
Yennawar, N. H., Li, L. C., Dudzinski, D. M., Tabuchi, A., and Cosgrove, D. J. (2006). Crystal structure and activities of EXPB1 (Zea m 1), alpha, betaexpansin and group-1 pollen allergen from maize. Proc. Natl. Acad. Sci. U.S.A. 103, 14664-14671. doi: 10.1073/pnas.0605979103

Yin, Y., Vafeados, D., Tao, Y., Yoshida, S., Asami, T., and Chory, J. (2005). A new class of transcription factors mediates brassinosteroid-regulated gene expression in Arabidopsis. Cell 120, 249-259. doi: 10.1016/j.cell.2004.11.044

Zhao, C., Wang, P., Si, T., Hsu, C. C., Wang, L., Zayed, O., et al. (2017). MAP kinase cascades regulate the cold response by modulating ICE1 protein stability. Dev. Cell 43, 618-629. doi: 10.1016/j.devcel.2017.09.024

Zhao, C., Zhang, Z., Xie, S., Si, T., Li, Y., and Zhu, J. K. (2016). Mutational evidence for the critical role of CBF Transcription Factors in cold acclimation in Arabidopsis. Plant Physiol. 171:00533. doi: 10.1104/pp.16. 00533

Conflict of Interest: The authors declare that the research was conducted in the absence of any commercial or financial relationships that could be construed as a potential conflict of interest.

Copyright (c) 2020 Ramirez and Poppenberger. This is an open-access article distributed under the terms of the Creative Commons Attribution License (CC BY). The use, distribution or reproduction in other forums is permitted, provided the original author(s) and the copyright owner(s) are credited and that the original publication in this journal is cited, in accordance with accepted academic practice. No use, distribution or reproduction is permitted which does not comply with these terms. 